\title{
Topical glyceryl trinitrate relaxes the sphincter of Oddi
}

\author{
W Luman, A Pryde, R C Heading, K R Palmer
}

\begin{abstract}
Background/Aim-Nitric oxide (NO) may be involved in non-adrenergic noncholinergic (NANC) inhibitory innnervation of the sphincter of Oddi (SO). The effects of topical application of glyceryl trinitrate (GTN), a NO donor, upon SO motility were examined.

Methods-Nineteen patients undergoing routine SO manometry for investigation of abdominal pain were studied. After routine recording of SO motility, they were randomised into three groups to receive $10 \mathrm{ml}$ of normal saline, $5 \mathrm{mg}$ GTN $(0.5 \mathrm{mg} / \mathrm{ml})$ or $10 \mathrm{mg}(1 \mathrm{mg} / \mathrm{ml})$ GTN. Drug solutions were infused topically onto papilla via the manometry catheter and recordings were continued for a further 5 minutes.

Results-There was no significant change in SO motor variables following application of normal saline. GTN reduced SO tonic and phasic contractions. In four patients, there was complete abolition of all phasic contraction.

Conclusions-Local application of GTN inhibits SO motility. This may have application for diagnostic and therapeutic biliary endoscopy.

(Gut 1997; 40: 541-543)
\end{abstract}

Keywords: glyceryl trinitrate, sphincter of Oddi.

Delivery of bile into duodenum is controlled by hepatic bile secretion, gall bladder contraction and the sphincter of Oddi (SO). The hormone cholecystokinin (CCK) is believed to be responsible for postprandial gall bladder contraction and SO relaxation. Recent studies have shown that the effect of CCK upon the SO is mediated through stimulation of the nonadrenergic non-cholinergic (NANC) nerves ${ }^{1}$ and nitric oxide (NO) is an important element of this pathway. ${ }^{2-4}$

There have been few studies on the effect of NO on the function of the SO. Slivka et al localised the presence of NO synthase (NOS) in nerve fibres and bundles of human SO and demonstrated that topical application of $S$-nitroso- $\mathrm{N}$-acetylcysteine (SNAC), an NO donor, inhibits SO motility. ${ }^{5}$ However, SNAC needs to be freshly prepared, is not stable over a prolonged period of time, and is not widely available. The aim of the present study was to examine the effect of glyceryl trinitrate (GTN; Nitrocine, Schwarz Pharma, UK), a form of NO donor that is commercially available, on SO motility.

\section{Methods}

PATIENTS

Patients undergoing routine SO manometry for investigation of upper abdominal pain were examined. The majority of patients underwent manometry for investigation of postcholecystectomy pain with a median duration of $2 \cdot 1$ (SD 1-5) years after surgery. Only two patients still had gall bladder in situ. None of the patients was on regular medication with nitrates or calcium channel blockers. All of the patients had been investigated with normal abdominal ultrasound scans and endoscopic retrograde cholangiopancreatography (ERCP) before manometry.

\section{SO MANOMETRY}

After an overnight fast, patients were sedated with 5-10 $\mathrm{mg}$ intravenous midazolam. A standard triple lumen polyethylene manometric catheter (SOM-21-LEHMAN, Wilson Cook Medical Inc, Winston-Salem, USA) with an external diameter of $1.7 \mathrm{~mm}$ and luminal diameter of $0.5 \mathrm{~mm}$, was introduced into the common bile duct via an Olympus JFIT10 duodenoscope. The manometric catheter had a length of $200 \mathrm{~cm}$ with three lateral openings of $0.5 \mathrm{~mm}$ in diameter at $2 \mathrm{~mm}$ intervals. The most distal end of the catheter was marked by six black rings $2 \mathrm{~mm}$ apart to facilitate positioning of catheter in relation to the ampulla.

The catheter was perfused continuously with sterile water using a low compliance pneumohydraulic capillary infusion pump (Arndorfer Medical Specialities, Wisconsin, USA) at a flow rate of $0.25 \mathrm{ml} / \mathrm{min}$. This was connected via a transducer to a computerised polygraph (Albyn Medical Version 6.0, UK). The transducer was calibrated before each study and catheter lumen occlusion produced a pressure rise in excess of $250 \mathrm{~mm} \mathrm{Hg} / \mathrm{s}$.

After recording duodenal pressure, which was taken as the zero reference, the papilla was cannulated and the catheter was withdrawn across the $S O$ in $2 \mathrm{~mm}$ increments using the black marks on the catheter as a guide. Recordings were obtained for at least 60 seconds at each station. After two such pullthroughs, the catheter was repositioned so that the distal two channels were recording phasic SO contractions. The most proximal channel was therefore located just outside the papilla. Patients were randomised into three groups. The first group of patients received topical application of $10 \mathrm{ml}$ normal saline; the two other groups received $10 \mathrm{ml}$ of GTN at either $10 \mathrm{mg}(1 \mathrm{mg} /$ $\mathrm{ml}$; GTN 10) or $5 \mathrm{mg}$ (diluted with $5 \mathrm{ml}$ of

\footnotetext{
Correspondence to: Gr K R Palmer, Western General Hospital, Crewe Road, Edinburgh. Accepted for publicatio 28 November 1996

Gastrointestinal U Hospital, Ed
} 
Baseline manometric motor variables. Results are expressed as mean (SE)

\begin{tabular}{lccc}
\hline & Saline & GTN $5(\mathrm{mg} / \mathrm{ml})$ & GTN $10(\mathrm{mg} / \mathrm{ml})$ \\
\hline Mean duodenal pressure (mm Hg) & $26(4)$ & $23(3)$ & $23(3)$ \\
Mean CBD pressure (mm Hg) & $15(4)$ & $6(4)$ & $10(3)$ \\
SO motor characteristics: & $31(2)$ & $17(3)$ & $33(4)$ \\
Basal (mm Hg) & $109(6)$ & $78(7)$ & $84(18)$ \\
Amplitude (mm Hg) & $6(1)$ & $5(0 \cdot 3)$ & $5(2)$ \\
Duration (s) & $6(2)$ & $4(0 \cdot 3)$ & $7(2)$ \\
Frequency (per min) & $496(118)$ & $312(35)$ & $462(125)$ \\
Motility index (mm Hg min) & &
\end{tabular}

$\mathrm{CBD}=$ common bile duct.

normal saline to $0.5 \mathrm{mg} / \mathrm{ml}$; GTN 5). The proximal channel was disconnected from the perfusion system and the drug solutions were then infused into the channel over 1 minute. Recording was started immediately at the end of drug infusion for a 5 minute period.

\section{Analysis of manometric recordings}

Manometric tracings were coded and analysed by an experienced observer (AP) who was blinded to the infusion material. Common bile duct pressure, basal SO pressure and amplitude of the phasic contractions of the sphincter were determined with reference to the intraduodenal pressure. The mean amplitude of phasic contractions was calculated as the average of contractile amplitude minus basal pressure in each of the three channels. Average phasic contractile frequency was calculated as the number of phasic contractions divided by duration of recording period during which contractions were identified. The duration of phasic contraction in seconds was measured from the onset of the major upstroke to the end of the wave. A motility index was calculated as the product of mean amplitude and frequency. Duodenal motor activity was monitored using a separate catheter which was taped to the outside of the endoscope. Contractile activity which occurred simultaneously with duodenal contractions was ignored as it was felt to be secondary to duodenal contractions.

\section{STATISTICAL ANALYSIS}

All data are reported as mean (SE) unless otherwise stated. Paired Student's $t$ tests were
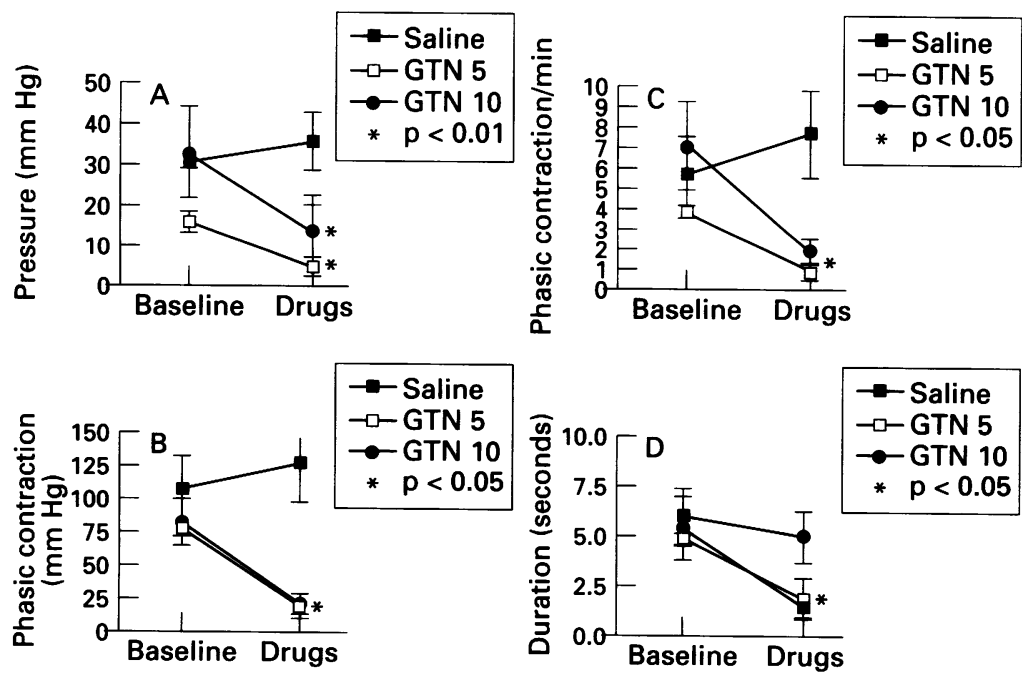

Figure 1: Change in basal SO tonic contraction $(A)$, amplitude $(B)$, frequency $(C)$, and duration (D) of phasic contraction with the different infusions. used to compare variables before and after injection. Differences with $p$ values of less than 0.05 were considered significant.

The study was approved by the Lothian ethics subcommittee for medicine and oncology.

\section{Results}

Nineteen patients were recruited into the study. There were 17 females; the median age was 41 (range 29-61) years. Five patients were randomised to saline injection; two groups of seven patients were each randomised to either $5 \mathrm{mg}$ or $10 \mathrm{mg} \mathrm{GTN}$.

The baseline results of SO motor activity are presented in the Table. Apart from the basal SO pressure, the means of all the motor variables were within normal limits as defined by previous studies using a similar perfusion technique in healthy volunteers. ${ }^{6-8}$ The basal SO pressures are slightly higher than previously reported. This is because some of these patients had SO dysfunction according to previously defined criteria. ${ }^{9}$ One patient exhibited a basal SO tonic pressure of $90 \mathrm{~mm}$ $\mathrm{Hg}$ accompanied by tachyoddia (frequency of 12 contraction per second); she was randomised to saline. The second patient who was randomised to $10 \mathrm{mg}$ GTN also had tachyoddia although tonic SO pressure was normal.

There was a non-significant increase in basal SO tonic pressure, amplitude and frequency of phasic activity after injection of $10 \mathrm{ml}$ normal saline (Fig 1). In contrast, mean tonic SO basal pressure and all the variables of phasic SO activity significantly diminished after injection with $5 \mathrm{mg}$ and $10 \mathrm{mg}$ GTN; specifically, phasic contractions became significantly less frequent, were shorter in duration, and had decreased amplitude. Consequently, the motility indices fell from 312 (35) $\mathrm{mm} \mathrm{Hg}$ min to 40 (19) $\mathrm{mm}$ $\mathrm{Hg}$ min in the group who received GTN $5 \mathrm{mg}$ and from 462 (125) to 57 (27) $\mathrm{mm} \mathrm{Hg}$ min in the higher dose GTN group (Fig 2). These effects were seen both in patients who had normal SO function and in those who had abnormal SO motility.

The duration of GTN inhibition of the SO was approximately 2 minutes. Although duodenal motility was not quantitated, video recording also showed cessation of contractility.

\section{Discussion}

We have domonstrated that topical application of GTN but not normal saline significantly inhibited SO tonic and phasic activity. Doses of 5 and $10 \mathrm{mg}$ GTN had similar efficacy with a duration of approximately 2 minutes in both cases.

In the human gastrointestinal tract, nonadrenergic non-cholinergic (NANC) innervation is important in nerve mediated relaxation and membrane hyperpolarisation ${ }^{4}$ and present evidence indicates that NO is a NANC neurotransmitter. ${ }^{10} \mathrm{NO}$ is synthesised from Larginine by the enzyme nitric oxide synthase (NOS); NO then activates soluble guanylate cyclase, catalysing formation of cyclic GMP 


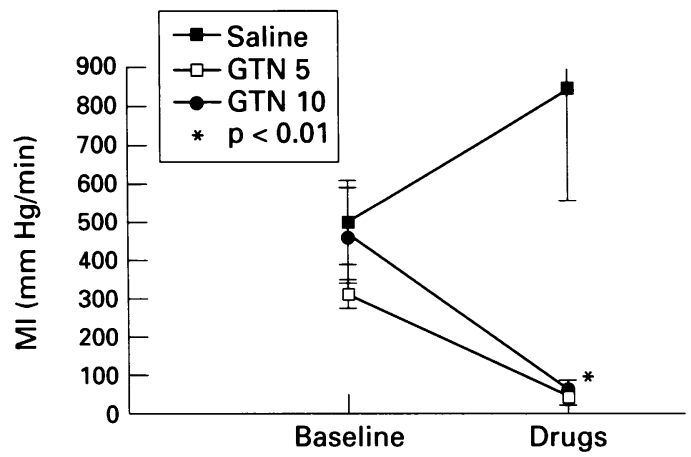

Figure 2: Change in motility index (MI) with the different infusions.

which is an inhibitor of smooth muscle contraction. ${ }^{11}$ Identification of NOS in a subpopulation of myenteric nerves supports the physiological role of $\mathrm{NO}$ in the regulation of intestinal motility. Complex neurogenic and hormonal mechanisms are involved in the control of SO muscle tone and motility. Ingestion of a meal ${ }^{12}$ and injection of $\mathrm{CCK}^{13}$ produce a decrease in SO basal pressure and amplitude and reduce the frequency of phasic contractions, thereby facilitating bile flow into the duodenum. The inhibitory effect of CCK is believed to be mediated through NANC inhibitory nerves. ${ }^{1} \mathrm{NO}$ has been demonstrated to control SO motility in animals ${ }^{5}{ }^{14-17}$ and the presence of NOS has been confirmed in the SO neurons of rabbits. ${ }^{51518}$ In humans, NOS has been localised to nerve bundles and fibres by NADPH diaphorase immunohistochemical staining and topical application of SNAC inhibits SO motility. ${ }^{5}$

In humans, sublingual GTN was found to be effective in improving post-cholecystectomy pain associated with SO dysfunction although side effects limited its therapeutic potential. ${ }^{19}$ Staritz et al demonstrated that sublingual GTN lowered SO basal pressure and contraction amplitude during SO manometry. In contrast with our findings, SO frequency was not inhibited but this difference could be attributed to drug dosage and mode of administration. ${ }^{20}$ The same investigators subsequently showed that common bile duct stones between 6 and $12 \mathrm{~mm}$ in diameter could be removed from an intact papilla after GTN induced SO relaxation. $^{21}$ Sublingual GTN spray could facilitate papillary cannulation during ERCP. ${ }^{22}$

We speculate that topical application of GTN could be of clinical application during ERCP as it inhibits both duodenal and SO motility. When administered orally, sublingual GTN can cause headache and may cause hypotension. Local administration to the papilla was not associated with systemic effects and high volumes can be targeted to the SO. This may have advantages over the administration of systemic drugs. It would be helpful in inhibiting duodenal and SO motility for patients in whom buscopan or glucagon are contraindicated. It could also facilitate extraction of small stones from the biliary tree without resort to sphincterotomy or papillary balloon dilatation. However, its duration of action is relatively short and this may limit its clinical application.

In summary, our present study showed that topical application of GTN, an NO donor, inhibits SO tonic and phasic contraction. This mode of GTN delivery may be of clinical application during ERCP cannulation and stone extraction.

1 Behar J, Biancani P. Pharmacologic characterisations of excitatory and inhibitory cholecystokinin receptors of the cat gallbladder and sphincter of Oddi. Gastroenterology 1987; 92: 764-70.

2 Gillespie JS, Liu X, Martin W. The effects of L-arginine and $\mathrm{N}^{\mathrm{G}}$-monomethyl L-arginine on the response of the rat anococygeus muscle to NANC nerve stimulation. $\mathrm{Br} \mathcal{F}$ anococygeus muscle to NANC

3 Gibson A, Mirzazadeh S, Hobbs AJ, Moore PK. L-NG monomethyl arginine and $\mathrm{L}-\mathrm{N}^{\mathrm{G}}$-nitro arginine inhibit non-adrenergic, non-cholinergic relaxation of the mouse anococygeus muscle. Br f Pharmacol 1990; 99: 602-6.

4 Bult H, Boeckxstaens GE, Pelckmans PA, Jordaens FH, Van Maercke YM, Herman AG. Nitric oxide as an inhibitory non-adrenergic non-cholinergic neurotransmitter. Nature 1990; 345: 346-7.

5 Slivka A, Chuttani R, Carr-Locke DL, et al. Inhibition of sphincter of Oddi function by the nitric oxide carrier $\mathrm{S}$-nitroso-N-acetylcysteine in rabbits and humans. $\mathcal{J}$ Clin Invest 1994; 94: 1792-8.

6 Toouli J, Roberts-Thompson IC, Dent J, Lee J. Manometric disorders in patients with suspected sphincter of Oddi dysfunction. Gastroenterology 1985; 88: 1243-50.

7 Geenen JE, Hogan WJ, Dodds WJ, Toouli J, Venu RP. The efficacy of endoscopic sphincterotomy after cholecystectomy in patients with sphincter of Oddi dysfuncion. $N$ Engl f Med 1989; 320: 320-7.

8 Guelrud M, Mendoza S, Rossiter G, Villegas MI. Sphincter of Oddi in healthy volunteers. Dig Dis Sci 1990; 35: 38-46.

9 Funch-Jensen $P$. The clinical value of sphincter of Odd manometry. In: The sphincter of Oddi primer for the pancreaticobiliary endoscopist. Philadelphia: WB Saunders, 1993: 119-31.

10 Stark ME, Szurszewski JH. Role of nitric oxide in gastrointestinal and hepatic function and disease. Gastroenterology 1991; 103: 1928-49.

11 Ignarro LJ, Buga GM, Wood KS, Byrns RE, Chaudhuri G. Endothelium-derived relaxing factor produced and Endothelium-derived relaxing factor produced and
released from artery and vein is nitric oxide. Proc Natl released from artery and vein is
Acad Sci USA 1987; 84: 9265-9.

12 Worthy CS, Baker RA, Iannos J, Saccone GTP, Toouli J. Human fasting and postprandial sphincter of Oddi motility. Br f Surg 1989; 76: 709-14.

13 Toouli J, Hogan WJ, Geenen JE, Dodds WJ, Arndorfer RC. Action of cholecystokinin-octapeptide on sphincter of Oddi basal pressure and phasic wave activity in humans. Surgery 1980; 92: 497-503.

14 Kaufman HS, Shermak MA, May CA, Pitt HA, Lillemoe KD. Nitric oxide inhibits resting sphincter of Oddi activity. Am 7 Surg 1995; 165: 74-80.

15 Thune A, Delbro DS, Nilson B, Friman S, Svanvik J. Role of nitric oxide in motility and secretions of the feline of nitric oxide in motility and secretions of the feline hepatobiliar 20 .

16 Baker RA, Saccone GTP, Brookes SJH, Toouli J. Nitric oxide mediates nonadrenergic, noncholinergic neural relaxation in the australian possum. Gastroenterology 1993; 105: $1746-53$

17 Mourelle M, Guarner F, Moncada S, Malagelada J. The arginine/nitric oxide pathway modulates sphincter of Oddi motor activity in guinea pigs and rabbits. Gastroenterology 1993; 105: 1299-305.

18 Toouli J, Baker RA. Innervation of the sphincter of Oddi: physiology and considerations of pharmacological intervention in biliary dyskinesia. Pharmacol Ther 1991; 49: vention $269-81$.

19 Cuer JC, Abergel A, Dapoigny M, Lhopital F, Bommelaer G, Laugier R. The efficacy of glyceryl trinitrate in patients with sphincter of Oddi dysfunction. A prospective doubleblind study. Gastroenterology 1995; 108: A412.

20 Staritz M, Poralla T, Ewe K, Meyer zum Buschenfelde K Effect of glyceryltrinitrate on the sphincter of Odd motility and baseline pressure. Gut 1985; 26: 194-7.

21 Staritz M, Poralla T, Dormeyer H, Meyer ZBK-H. Endoscopic removal of common bile duct stones through the intact papilla after medical sphincter dilation. Gastroenterology 1985; 88: 1807-11.

22 Donnellan I, Hallissey M, Nwokolo C, Loft D, Fraser I. Sublingual GTN spray improves success at ERCP cannulation [abstract]. Gut 1994; 35 (suppl 5): S36. 